\title{
A COMPARISON OF WILSON AND HOHMANN OSTEOTOMIES IN THE TREATMENT OF HALLUX VALGUS
}

\author{
DAVID GRACE, JANET HUGHES, LESLIE KLENERMAN
}

From the Northwick Park Hospital and Clinical Research Centre, Harrow, and the Royal National Orthopaedic Hospital, London

In a retrospective study we compared the results of 31 Wilson and 31 Hohmann osteotomies of the first metatarsal in the treatment of hallux valgus. There were no differences between the two operations in terms of patient satisfaction, pain relief, appearance, footwear and walking ability. First metatarsal shortening was the same after both operations, and the degree of shortening was unrelated to either the clinical or the pedobarographic findings.

Although the long-term radiographic changes after the Hohmann osteotomy were more worrying, the pedobarographic patterns tended to be worse after the Wilson osteotomy. There were no poor results and the numbers of feet with the same final grade were identical in each group. However, there was abnormal loading of the lateral metatarsal heads after both osteotomies when compared with the normal foot, and halluxcontact time during the stance phase was also significantly reduced after osteotomy.

Studies which directly compare the results of two different osteotomies of the first metatarsal in the treatment of hallux valgus are relatively uncommon despite numerous reports of individual procedures. Moreover, the long-term radiological and biomechanical changes which may follow osteotomy have seldom been investigated. Avascular changes in the first metatarsal head may occur (Mann 1982) and shortening of the first metatarsal may cause excessive loading of the lesser metatarsal heads, leading to metatarsalgia and callosities (Morton 1935; Hawkins, Mitchell and Hedrick 1945; Carr and Boyd 1968; Shapiro and Heller 1975). A detailed study was therefore undertaken to compare two simple osteotomies used for the correction of hallux valgus, paying particular attention to the radiological and pedobarographic findings at follow-up.

\section{PATIENTS AND METHODS}

In a retrospective study, 39 patients admitted to the Royal National Orthopaedic Hospital for the operative correction of hallux valgus were reviewed. Thirty-one feet had been treated by a Wilson osteotomy (Wilson

D. L. Grace, FRCS, Senior Orthopaedic Registrar

St Bartholomew's Hospital, West Smithfield, London ECl 7BE, England.

J. R. Hughes, BA, MCSP, Research Assistant

Northwick Park Hospital and Clinical Research Centre, Watford

Road, Harrow HAI 3UJ, England.

L. Klenerman, ChM, FRCS, Professor of Orthopaedic and Accident Surgery

Royal Liverpool Hospital, Prescot Street, Liverpool L7 8XP, England.

Requests for reprints should be sent to Professor L. Klenerman.

(C) 1988 British Editorial Society of Bone and Joint Surgery

$0301-620 X / 88 / 2052 \$ 2.00$

J Bone Joint Surg [Br] 1988;70-B: 236-41.
1963) and 31 feet by a Hohmann (1921) osteotomy (Table I). The chief indication for surgery was a painful bunion, but ill-fitting shoes and unsightly appearance were additional considerations.

Table I. Details of the two groups

\begin{tabular}{|c|c|c|}
\hline & $\begin{array}{l}\text { Wilson } \\
\text { osteotomy }\end{array}$ & $\begin{array}{l}\text { Hohmann } \\
\text { osteotomy }\end{array}$ \\
\hline $\begin{array}{l}\text { Number of patients } \\
\text { Number of women } \\
\text { Bilateral procedures } \\
\text { Number of feet }\end{array}$ & $\begin{array}{l}21 \\
20 \\
10 \\
31\end{array}$ & $\begin{array}{l}18 \\
18 \\
13 \\
31\end{array}$ \\
\hline $\begin{array}{l}\text { Average duration of symptoms (years) } \\
\text { Average duration of symptoms (years) } \\
\text { Average duration of cast-wearing (weeks) } \\
\text { Duration of follow-up (years) }\end{array}$ & $\begin{array}{l}30(16-63) \\
5(1-27) \\
8(6-10) \\
6.5(1-12)\end{array}$ & $\begin{array}{l}39(21-60) \\
8(1-22) \\
7(6-11) \\
5(1-10)\end{array}$ \\
\hline
\end{tabular}

Operative technique. Both operations were performed through a short dorsomedial incision. In the Wilson osteotomies (Fig. 1) a flap of the capsule and the medial collateral ligament were dissected from the medial exostosis, which was then resected. A $45^{\circ}$ oblique osteotomy was fashioned through the distal metatarsal shaft using an oscillating saw (though Wilson himself uses an osteotome). The distal fragment was then displaced laterally and proximally by about half the width of the bone, with slight displacement plantarward. A degree of stability was then afforded by suturing the flap of medial capsule under tension, either to the periosteum or through a drill-hole in the metatarsal shaft.

In the Hohmann osteotomies (Fig. 2) the periosteum was elevated circumferentially from the metatarsal neck and, using a power saw, a medially-based wedge of bone was excised. The osteotomy was then closed and the metatarsal head was displaced laterally by a few 
millimetres and transfixed to the shaft using a single percutaneous Kirschner wire.

Below-knee plaster casts were routinely applied after both operations; these casts were generally changed at two weeks without anaesthesia. Kirschner wires were removed from the Hohmann osteotomies in the outpatient clinic at six weeks. Other details are shown in Table I.

Review. When the patients attended for a final review, their overall satisfaction, pain relief, appearance, footwear and walking ability were recorded on percentage

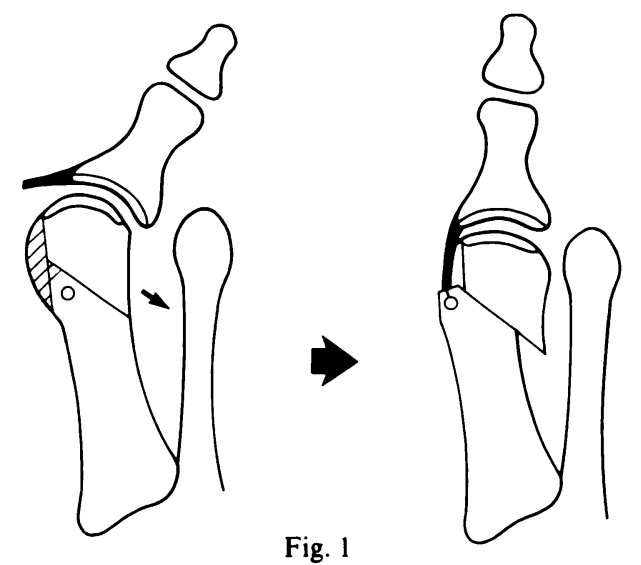

Fig. 1
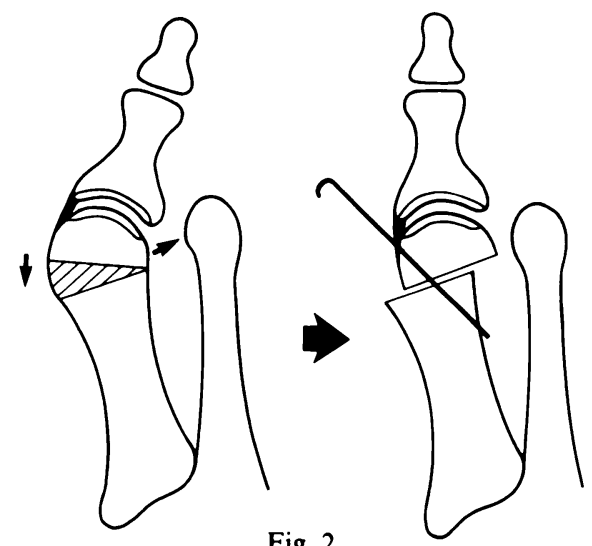

Fig. 2

Figure 1 - The Wilson osteotomy: an oblique osteotomy at a $45^{\circ}$ angle through the distal shaft of the first metatarsal with medial capsular plication. Figure 2-The Hohmann osteotomy: a transverse, medial closing-wedge osteotomy through the first metatarsal neck; this was modified by limited lateral displacement of the head and temporary percutaneous Kirschner-wire fixation.

linear analogue scales (Downie et al. 1978). The feet were inspected for evidence of callosities, and the range of movement in the joints was recorded. Maximum passive dorsiflexion of the first metatarsophalangeal joint was measured from a video image of the weight-bearing foot, with adhesive markers placed on the skin overlying the tarsometatarsal, metatarsophalangeal and interphalangeal joints of the hallux (Fig. 3).

Anteroposterior and lateral weight-bearing radiographs of the foot were taken before and after surgery, after union of the osteotomy and again at review. Hallux valgus angles and first-intermetatarsal angles were measured from these films. First-metatarsal shortening was expressed as a percentage of the pre-operative distance between a predetermined and reproducible landmark in the hindfoot and the articular surface of the first metatarsal head (Fig. 4). The apparent length of the

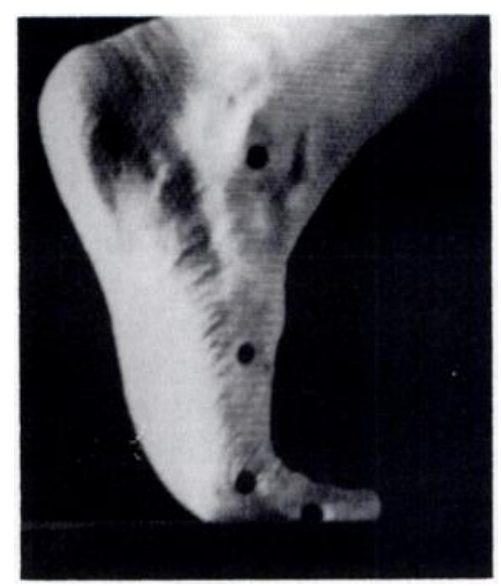

Fig. 3

Maximum dorsiflexion of the hallux measured directly from a video image.

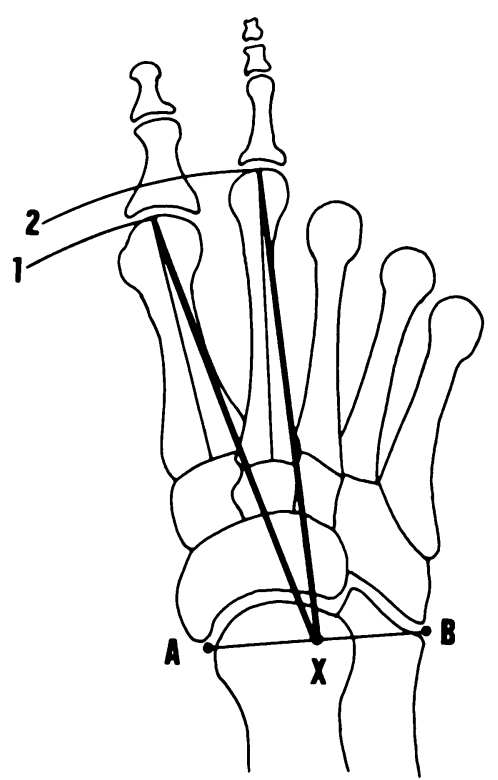

Fig. 4

Method of measuring first metatarsal shortening. $X$ is the midpoint of $A B$. The percentage shortening of the first metatarsal is then expressed as:

$$
\frac{X I \text { (pre-op) }}{X 2 \text { (pre-op) }} \div \frac{X 1 \text { (post-op) }}{X 2 \text { (post-op) }} \times 100
$$

second metatarsal was used as a control to eliminate errors resulting from different magnification or positioning between the pre- and postoperative radiographs. The extent of plantar displacement or angulation at the osteotomy was recorded from the lateral film. Degenerative changes in the first metatarsophalangeal joint and alterations in bone texture were noted. 
Dynamic foot pressure patterns were recorded at follow-up using a pedobarograph with the Sheffield system of automatic analysis (Duckworth et al. 1982).

\section{RESULTS}

The majority of patients reported higher than $50 \%$ overall satisfaction after both operations, although few patients were totally satisfied with the surgical result (Figs 5 and 6). After Hohmann osteotomy, satisfaction was more variable, with more feet being either very satisfactory or unsatisfactory.

Two-thirds of the patients were completely pain free at follow-up, and only a small number of feet remained significantly painful after both osteotomies (Figs 7 and 8). Relatively few patients in either group were dissatisfied with the shape of their foot or feet (Figs 9 and 10 ), and difficulties with shoe-fitting and walking were rarely expressed. Statistical analysis failed to demonstrate any significant differences between the two osteotomies for any of the above parameters.

Average dorsiflexion of the first metatarsophalangeal joint was $61^{\circ}\left(30^{\circ}\right.$ to $\left.90^{\circ}\right)$ after a Wilson and $65^{\circ}\left(30^{\circ}\right.$ to $90^{\circ}$ ) after a Hohmann osteotomy.

Radiological findings. The average improvement in the hallux valgus and first-intermetatarsal angles were similar for both osteotomies (Table II). The percentage shortening of the first metatarsal averaged $6.3 \%(1.7 \%$ to $11 \%)$ after a Wilson and $6.4 \%(3.2 \%$ to $12.8 \%)$ after a Hohmann osteotomy. Neither the degree of shortening, nor the extent of dorsal or plantar displacement, or angulation at the osteotomy, bore any relationship to the clinical results.

Degenerative changes in the first metatarsophalangeal joint were more commonly observed at follow-up after Hohmann osteotomy despite the fact that fewer feet in this group showed pre-existing changes (see Fig. 1). Nine feet in this group also had an elliptical subchondral lucent zone situated centrally within the metatarsal head (see Fig. 12), associated with joint pain in three of the nine feet.

Pedobarograph findings. Four distinct pedobarograph patterns emerged (see Fig. 13).

Type 1. Equal maximum loading under the first and second metatarsal heads.

Type 2. Even loading under the second and third metatarsal heads.

Type 3. Isolated peak loading under a single lateral metatarsal head (usually the second).

Type 4. Maximum loading under the lateral three metatarsal heads.

The majority of feet in both osteotomy groups produced a Type 3 pattern, with peak loading under a single lateral metatarsal head (Table III). Nine feet in the Wilson group had a Type 4 pattern compared with only two feet from the Hohmann group. For individual feet, the pedobarographic pattern bore no relationship to either the clinical result, the degree of shortening or the extent of plantar displacement or angulation of the osteotomy. The unoperated opposite foot in the 16 patients who had a unilateral osteotomy were studied for comparison, and produced mainly Type 2 and 3 patterns.

For comparison, 78 feet in 39 age-matched volunteers with normal asymptomatic feet were also tested as controls, and these produced predominantly Type 1 and 2 patterns.

The length of time the hallux was in contact with the ground was recorded in milliseconds from individual frames of the dynamic pedobarograph. This was then expressed as a percentage of the total duration of stance phase, and averaged $50 \%(0 \%$ to $77 \%)$ after a Wilson and $60 \%(38 \%$ to $79 \%)$ after a Hohmann osteotomy. There was no statistical correlation between the toe-contact time and the type of osteotomy performed. For individual feet, there was no correlation with either the clinical result, the degree of first metatarsal shortening or the pedobarograph pattern. However, those feet in which the first metatarsal head had been measurably plantar-depressed by the osteotomy had significantly longer toe-contact times. The 16 untreated feet in the patients who had a unilateral osteotomy had an average toe-contact time of $74 \%(60 \%$ to $84 \%)$ and toe-contact time averaged $73 \%(50 \%$ to $89 \%)$ in the 78 normal control feet.

Complications. There were no serious complications. One instance of delayed wound healing was encountered after a Wilson osteotomy but there were no infections. Some loss of position occurred in 10 feet after Wilson osteotomy and these required a manipulative readjustment under general anaesthesia when the plaster was changed at two weeks. After Hohmann osteotomy, anaesthesia was needed also to re-insert a Kirschner wire in one foot, and to remove Kirschner wires in three. One non-union occurred after Hohmann osteotomy with an eventual satisfactory outcome after bone-grafting.

In the long-term, one foot from each group required further surgical intervention in the form of an exostectomy, but no foot required a revision osteotomy or a major salvage procedure.

Causes of dissatisfaction. Seven unsatisfactory results after Wilson osteotomy were due to recurrent deformity and stiffness in two feet, one painful first metatarsophalangeal joint, one painful second toe, one recurrence with metatarsalgia, one functionless hallux with painful callosities and one foot in which the cause of dissatisfaction was unclear. There were also seven unsatisfactory results after Hohmann osteotomy including three feet with metatarsalgia, two with painful recurrence, one with painless recurrence and one with stiffness and metatarsalgia.

Overall grading. The feet were classified according to criteria which had been defined at the outset of the study. Excellent. Surgeon and patient completely satisfied.

Good. No pain, slight recurrence of valgus, or some limitation of movement. 
Fair. Moderate recurrence, or exostosis, or metatarsalgia.

Poor. Severe recurrence, or severe degenerative changes in the joint.

The final gradings were identical in both osteotomy groups, with 11 excellent, 13 good, 7 fair and no poor results from each group. Hence, an excellent or good result was obtained in $77 \%$ of feet.

\section{DISCUSSION}

Of the many operations described for the correction of hallux valgus, most surgeons generally employ only one type of first metatarsal osteotomy to the exclusion of all

WILSON

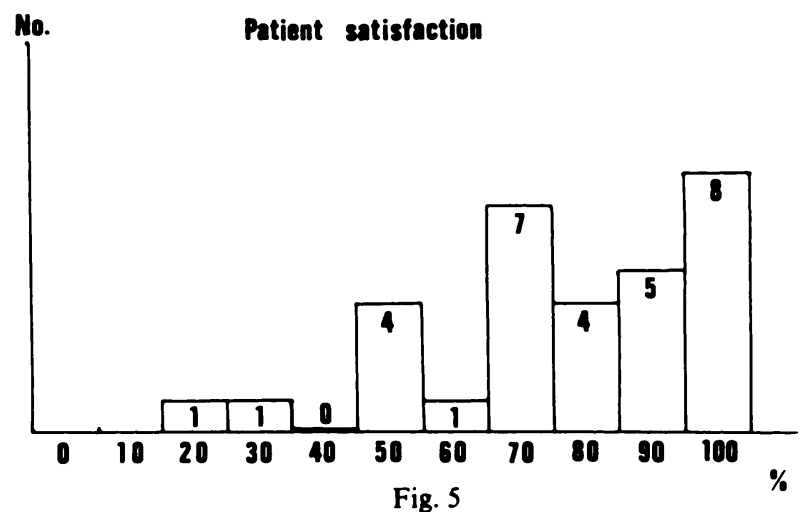

No.

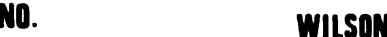

Pain

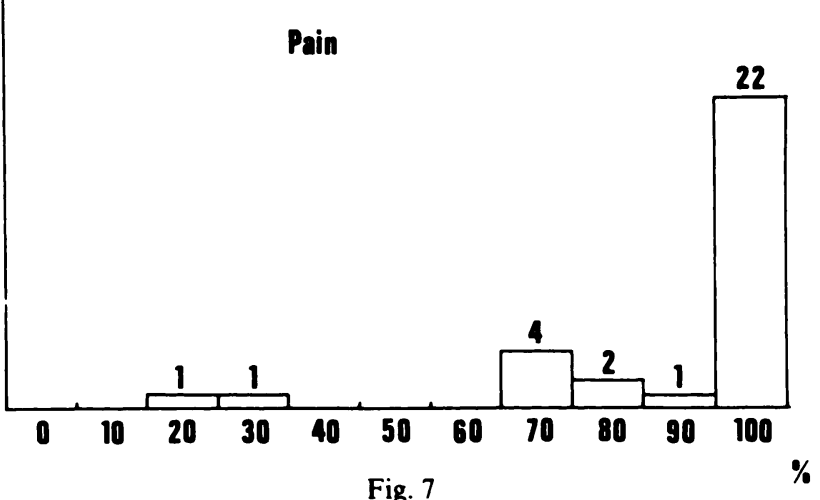

No.

WILSON
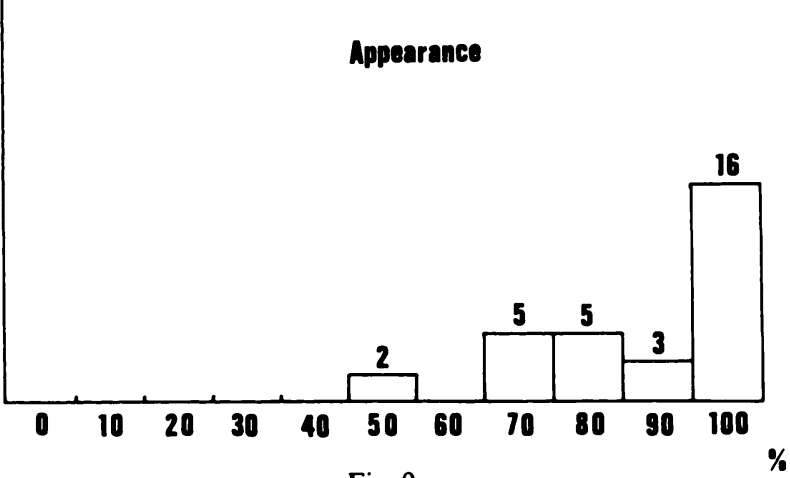

Fig. 9 the others. Rapid and consistent union, with permanent correction of deformity and relief of pain are the main objectives. Reported series show that success rates for most osteotomies are comparable, achieving satisfactory results in the region of $80 \%$ to $90 \%$.

Technical simplicity is an obvious advantage (Helal 1981) and the osteotomies compared in the present study are both easy to perform. Both, however, lack inherent stability and internal fixation was not advocated by either of the original authors. The Hohmann osteotomies in the present study were transfixed temporarily with a Kirschner wire, but loss of position occurred in 10 feet after Wilson osteotomy and might have been prevented

HOHMANN

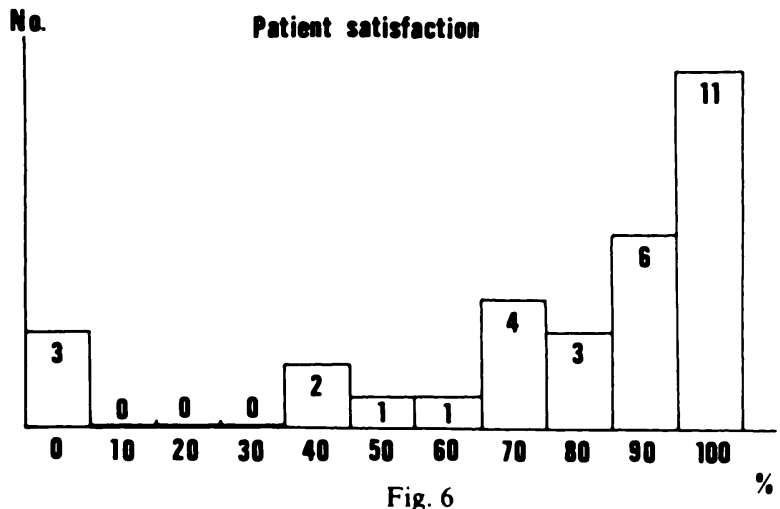

No.

HOHMANK

Pain

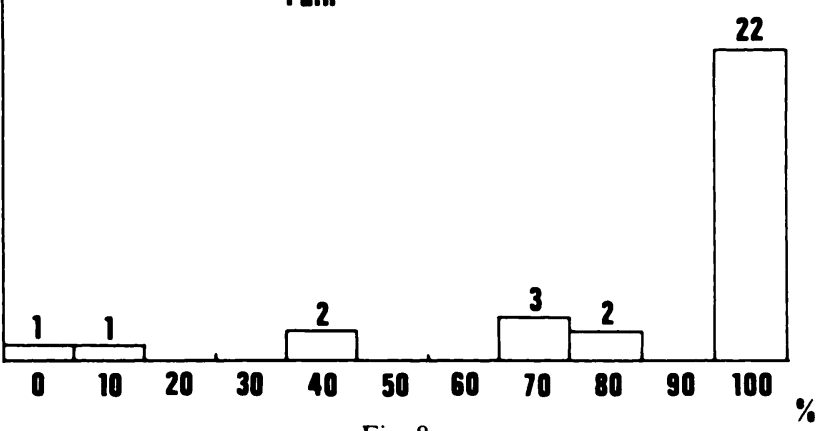

Fig. 8

No.

HOHMANK

Appearance

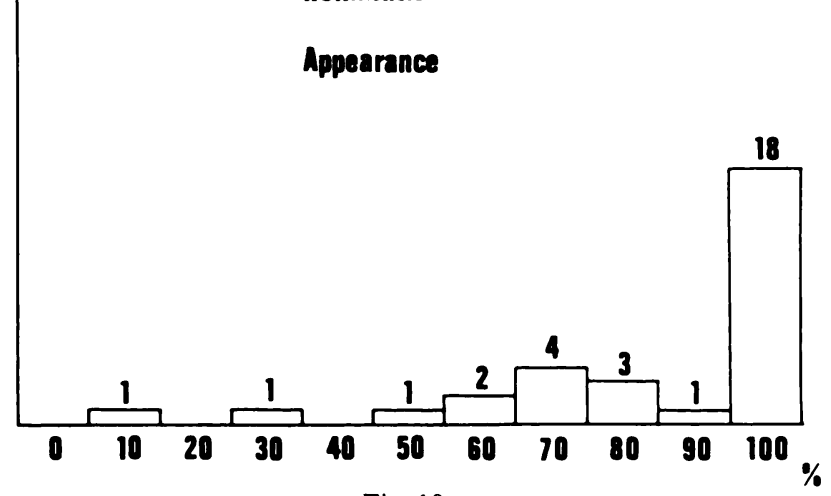

Fig. 10

Linear analogue scores for overall satisfaction, pain relief and appearance after osteotomy. Vertical axes show the number of feet, horizontal axes record the percentage. 
by using Kirschner wire (Pittman and Burns 1984) or screw fixation (Allen et al. 1981).

Stiffness might be expected to occur more often after Wilson osteotomy because the joint capsule is disturbed (Kelikian 1965; Wilson 1980; Helal 1981). However, the range of dorsiflexion was similar after both osteotomies, although only passive dorsiflexion was recorded. This is the most useful movement during normal walking, and the method of using skin markers and measuring directly from a video image was precise.

The obliquity of the Wilson osteotomy might be expected to shorten the first metatarsal more than the transverse Hohmann osteotomy. Indeed, when the studies of Dooley (1968), Allen et al. (1981) and Cetti and Christensen (1983) are combined, an average first metatarsal shortening of $7.3 \mathrm{~mm}$ in 118 Wilson osteotomies may be calculated. This is considerably greater than the $1.7 \mathrm{~mm}$ mean shortening reported by Zlotoff (1977) in seven feet after Hohmann/Reverdin osteotomy. However, previous methods of measuring absolute shortening in millimetres may be inaccurate due to differences in magnification. Although the method of measuring shortening in our study was somewhat complex, it allowed an extremely accurate comparison of the shortening produced by the two operations. Our results clearly show that shortening was the same after both osteotomies. Furthermore, the degree of shortening was unrelated to the clinical result, which would support the findings of Mitchell et al. (1958) and Gibson and Piggott (1962). However, many authors including Morton (1935), Hawkins et al. (1945), Carr and Boyd (1968), Shapiro and Heller (1975) and Merkel et al. (1983) reported that excessive shortening was undesirable and led to metatarsalgia, callosities and hammering of the second toe. The average length of follow-up in our study was less than six years, which may be insufficient for the development of these undesirable sequelae.

In the present study, the pedobarograph patterns and toe-contact times were similar for the two operations, although more feet in the Wilson group demonstrated excessive loading under the lateral three metatarsal heads (Type 4 pattern). Our pedobarographic findings clearly demonstrated that feet treated by a first metatarsal osteotomy have altered load-bearing characteristics when compared with normal feet. Miller and Stokes (1979) and Allen et al. (1981) found abnormal patterns of loading were already present in hallux valgus patients before surgery. It is worth noting that, in the present study, the unoperated feet of patients who underwent unilateral osteotomy showed increased lateral loading when compared with normal feet; this suggests an intrinsic structural abnormality which might contribute to the development of hallux valgus.

After osteotomy, Allen et al. (1981) found a lateral shift in the weight-bearing patterns, and suggested that this might be due to metatarsal shortening. However, our results failed to demonstrate any relationship between

\begin{tabular}{|c|c|c|}
\hline & WILSON & HOHMANN \\
\hline $\begin{array}{c}\text { PRE-OP } \\
\text { DEGEMERATIVE } \\
\text { CHAMGESS } \\
\end{array}$ & 5 & 3 \\
\hline OSTEOPHYTES & 5 & 10 \\
\hline IRREGULARITY & 11 & 14 \\
\hline FLATTENING & 2 & 8 \\
\hline SCLEROSIS & 4 & 3 \\
\hline CYSTS & 18 & 20 \\
\hline $\begin{array}{c}\text { SUBCHONDRAL } \\
\text { LUCENCY }\end{array}$ & 0 & $9 \begin{array}{c}4 \text { mild } \\
5 \text { marked }\end{array}$ \\
\hline $\begin{array}{l}\text { JOINT } \\
\text { SPACE } \\
\end{array}$ & $1.9 \mathrm{~mm}$. & $1.9 \mathrm{~mm}$. \\
\hline $\begin{array}{l}\text { LACK of } \\
\text { TRABECULAR } \\
\text { PAIIIERA }\end{array}$ & 8 & 18 \\
\hline $\begin{array}{l}\text { CHANGe } \\
\text { TRABECULAR } \\
\text { OLEECTION }\end{array}$ & 0 & 6 \\
\hline $\begin{array}{l}\text { STRESS } \\
\text { RELIEF }\end{array}$ & 16 & 3 \\
\hline
\end{tabular}

Fig. 11

Radiological changes at final review.

Table II. Mean and range of the hallux valgus and first intermetatarsal angles, given in degrees

\begin{tabular}{|c|c|c|}
\hline & Wilson osteotomy & Hohmann osteotomy \\
\hline $\begin{array}{c}\text { Hallux valgus an } \\
\text { Pre-operative } \\
\text { Postoperative } \\
\text { Follow-up }\end{array}$ & $\begin{array}{l}32(23 \text { to } 54) \\
11(-8 \text { to } 27) \\
15(-10 \text { to } 30)\end{array}$ & $\begin{array}{l}34(13 \text { to } 52) \\
15(-5 \text { to } 42) \\
18(0 \text { to } 38)\end{array}$ \\
\hline $\begin{array}{l}\text { First-intermetata } \\
\text { Pre-operative } \\
\text { Follow-up }\end{array}$ & $\begin{array}{r}11.4(5 \text { to } 20) \\
9.1(1 \text { to } 21)\end{array}$ & $\begin{array}{l}13.2(4 \text { to } 23) \\
10.8(1 \text { to } 18)\end{array}$ \\
\hline
\end{tabular}

Table III. Distribution of pedobarographic patterns after osteotomy, in unoperated feet, and in normal (asymptomatic) feet

\begin{tabular}{lccll}
\hline & $\begin{array}{l}\text { Wilson } \\
\text { osteotomy }\end{array}$ & $\begin{array}{l}\text { Hohmann } \\
\text { osteotomy }\end{array}$ & $\begin{array}{l}\text { Unoperated feet } \\
\text { in unilateral } \\
\text { cases }\end{array}$ & $\begin{array}{l}\text { Normal } \\
\text { asymptomatic } \\
\text { controls }\end{array}$ \\
\hline $\begin{array}{l}\text { Type 1 } \\
\text { Type 2 }\end{array}$ & 1 & 3 & 3 & 30 \\
Type 3 & 18 & 6 & 7 & 36 \\
Type 4 & 9 & 20 & 6 & 11 \\
$\begin{array}{l}\text { Total number } \\
\text { of feet }\end{array}$ & 31 & 2 & 0 & 1 \\
\hline
\end{tabular}

the degree of shortening and either the pedobarographic pattern or the toe-contact time. Failure to depress the first metatarsal head is considered by many authors to reduce load-bearing by the hallux (Hohmann 1921; Mygind 1953; Carr and Boyd 1968; Helal 1981; Jahss, Troy and Kummer 1985). This view is supported by our finding that toe-contact time was prolonged when the metatarsal head had been shifted plantarward, although this only applied to a relatively small number of feet. 


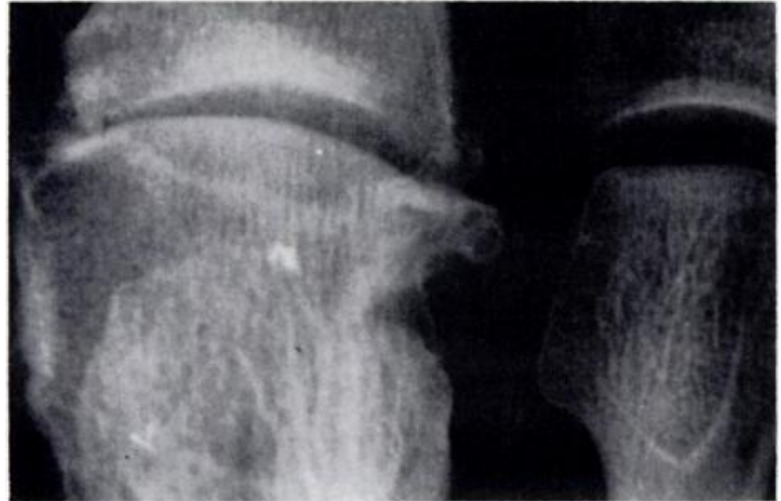

Fig. 12

Elliptical radiolucent defect in the subchondral bone of the metatarsal head in a foot treated by a Hohmann osteotomy.

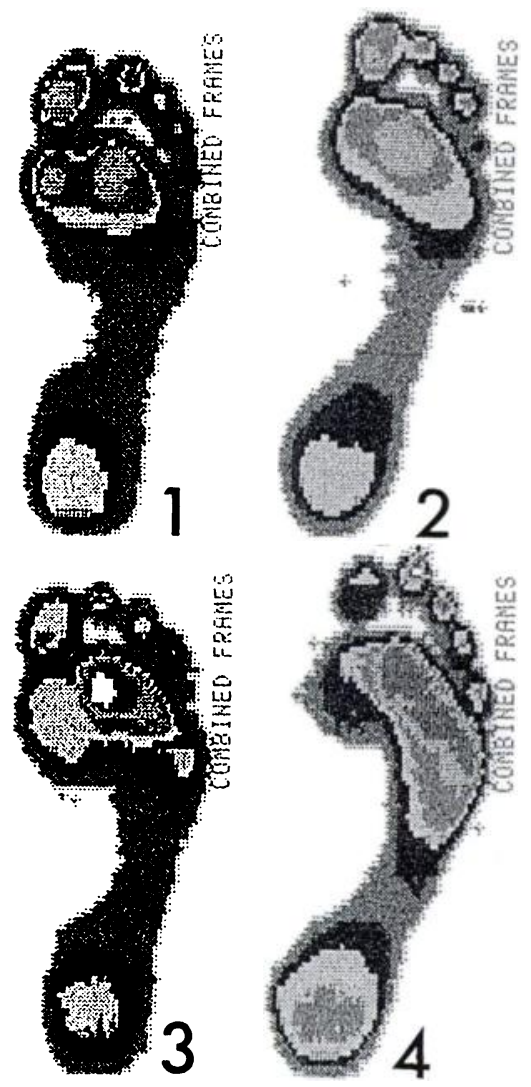

Fig. 13

The four pedobarographic patterns (see text).

The radiological changes after Hohmann osteotomy were slightly disconcerting. The significance of altered bone texture and trabecular pattern is uncertain, but there was a high incidence of degenerative changes in the first metatarsophalangeal joint at follow-up. The Hohmann osteotomy, being close to the joint may compromise the blood supply to the metatarsal head, and may be the cause of the subchondral lucent zones observed. This appearance may represent a degree of avascular necrosis of the metatarsal head as described by Mann in 1982. It tended to occur in older patients with pre-existing osteoarthritic changes, and perhaps the Hohmann osteotomy should be avoided in this group.

Wilson (1963), Helal (1981) and Cetti and Christensen (1983) have all reported success rates approaching $100 \%$ after a Wilson osteotomy. In the present study, the two osteotomies proved to be equally successful, although the overall $77 \%$ satisfactory results are slightly disappointing. This probably reflects the detailed nature of the study and the fairly stringent criteria applied for success. However, no patient had an obviously poor result or a serious complication.

The authors wish to thank Mr J. N. Wilson and Mr H. B. Kemp for allowing us to review their patients.

\section{REFERENCES}

Allen TR, Gross M, Miller J, Lowe LW, Hutton WC. The assessment of adolescent hallux valgus before and after first metatarsal osteotomy. Int Orthop 1981:5:111-5.

Carr CR, Boyd BM. Correctional osteotomy for metatarsus primus varus and hallux valgus. $J$ Bone Joint Surg $[\mathrm{Am}]$ 1968: 50-A : 1353-67.

Cetti R, Christensen S-E. Double oblique displacement osteotomy for hallux valgus. Acta Orthop Scand 1983;54:938-42.

Dooley BJ. Osteotomy of the metatarsal neck for hallux valgus. $J$ Bone Joint Surg [Br] 1968;50-B :677

Downie WW, Leatham PA, Rhind VM, Pickup ME, Wright V. The visual analogue scale in the assessment of grip strength. Ann Rheum Dis 1978:37:382-4.

Duckworth T, Betts RP, Franks CI, Burke J. The measurement of pressures under the foot. Foot Ankle 1982;3:130-41

Gibson J, Piggott H. Osteotomy of the neck of the first metatarsal in the treatment of hallux valgus: a follow-up of eighty-two feet. $J$ Bone Joint Surg [Br] 1962:44-B:349-55.

Hawkins FB, Mitchell CL, Hedrick DW. Correction of hallux valgus by metatarsal osteotomy. J Bone Joint Surg 1945:27:387 94.

Helal B. Surgery for adolescent hallux valgus. Clin Orthop $1981: 157: 50-63$

Hohmann G. Symptomatische oder physiologische Behandlung des Hallux valgus. Munc Med Wschr 1921:68:1042-5

Jahss MH, Troy AI, Kummer F. Roentgenographic and mathematical analysis of first metatarsal osteotomies for metatarsus primus varus: a comparative study. Foot Ankle 1985;5:280-321.

Kelikian H. Hallux valgus, allied deformities of the forefoot and metatarsalgia. Philadelphia, etc: WB Saunders, 1965.

Mann RA. Avascular necrosis (in letter to Editor). Foot Ankle 1982:3:125-9.

Merkel KD, Katoh Y, Johnson EW Jr, Chao EY. Mitchell osteotomy for hallux valgus: long-term follow-up and gait analysis. Foot Ankle 1983:3:189-96.

Miller GF, Stokes IAF. A study of the duration of load-bearing under different areas of the foot. Eng Med 1979;8:128-32.

Mitchell CL, Fleming JL, Allen R, Glenney C, Sanford GA. Osteotomybunionectomy for hallux valgus. $J$ Bone Joint Surg $[\mathrm{Am}]$ $1958: 40-A: 41-60$.

Morton DJ. The human foot: its etolution, physiology and functional disorders. New York: Columbia University Press, 1935.

Mygind HB. Some views on the surgical treatment of hallux valgus. Acta Orthop Scand 1953;23:152-8.

Pittman SR, Burns DE. The Wilson bunion procedure modified for improved clinical results. J Foot Surg 1984:23:314-20.

Shapiro F, Heller L. The Mitchell distal metatarsal osteotomy in the treatment of hallux valgus. Clin Orthop 1975;107:225-31.

Wilson DW. Treatment of hallux valgus and bunions. Br J Hosp Med $1980 ; 24: 548-59$.

Wilson JN. Oblique displacement osteotomy for hallux valgus. $J$ Bone Joint Surg [Br] 1963:45-B:552-6.

Zlotof H. Shortening of the first metatarsal following osteotomy and its clinical significance. J Am Podiatry Assoc 1977;67:412-26. 